\title{
FREQUENCY OF HYPERURICEMIA IN HYPERTENSIVE PATIENTS AND ITS ASSOCIATION WITH AGE OF PATIENT
}

\author{
Syed Saif Ul Hassan Shah, Usman Iqbal, Ejaz Ahmad \\ Combined Military Hospital Abbottabad/National University of Medical Sciences (NUMS) Pakistan
}

\begin{abstract}
Objective: To determine the frequency of hyperuricemia in hypertensive patients and its association with the age of patients.

Study Design: Cross sectional analytical study.

Place and Duration of Study: Combined Military Hospital Abbottabad, from Sep 2016 to Feb 2017.

Methodology: All patients of 18-70 years of age with either gender presenting in and out patient departments with hypertension were enrolled. Serum uric acid was measured. Analysis of serum uric was done with Selectra $\mathrm{XL}$ chemical analyzer having normal references range of 2.52-6.97 mg/dl for males and 1.51-6.0 mg/dl for females. Reports were verified by Pathologist.

Results: A total of 137 patients were selected for the study. Mean age of the patients was $56.09 \pm 09.36$ years. There were $76(55.50 \%)$ patients with $>55$ years of age while $61(44.50 \%)$ patients were presented with $\leq 55$ years of the patients. Male preponderance was higher $83(61 \%)$ as compared to females $54(39 \%)$. Mean weight, height and Body Mass Index of the patients was $67.99 \pm 6.91$ kilograms, $1.63 \pm 0.08$ meters and $25.32 \pm 2.15 \mathrm{~kg} / \mathrm{m}^{2}$ respectively. Mean systolic blood pressure of the patients was $166.71 \pm 13.67 \mathrm{mmHg}$. Mean Diastolic blood pressure was $100.15 \pm 8.84 \mathrm{mmHg}$. Mean serum uric acid level was $6.96 \pm 0.82 \mathrm{mg} / \mathrm{dl}$. Frequency of hyperuricemia was found in $102(74.45 \%)$ while normouricemia in $35(25.55 \%)$ patients.

Conclusion: Frequency of hyperuricemia was found higher in hypertensive patients and it was not associated with the age of patients.
\end{abstract}

Keywords: Hypertension, Hyperuricemia, Serum uric acid level.

This is an Open Access article distributed under the terms of the Creative Commons Attribution License (http://creativecommons.org/licenses/by/4.0), which permits unrestricted use, distribution, and reproduction in any medium, provided the original work is properly cited.

\section{INTRODUCTION}

One of the leading causes of death and disability across the globe is hypertension with 3.4 million deaths taking place worldwide in $2010^{1}$. In Pakistan, hypertension frequency was $16.2 \%$ in the rural and $21.6 \%$ in the urban population 2 .

Hyperuricemia is a condition in which there is abnormally higher level of uric acid is found in the blood or plasma. Nucleic acid metabolizes to gives rise to uric acid as the final and last product. Although purine can be taken orally but it contributes much less fraction of body purines as larger amount of purines is biosynthesized than taken orally ${ }^{3}$. The presence of uric acid-binding proteins increases the physiological solubility of uric acid to $7.0 \mathrm{mg} / \mathrm{dl}$ from normal value of 6 . This causes crystallization of uric acid in human

Correspondence: Dr Syed Saif Ul Hassan Shah, House No. 476, Lane-3, Gulistan Colony, Rawalpindi Pakistan

Received: 10 May 2019; revised received: 28 Dec 2019; accepted: 31 Dec 2019 body.

The value of serum uric acid can vary and depends on geographical location, gender, dietary habits and medications ${ }^{4}$. Adenosine Tri Phosphate is the major energy molecule in human body and its metabolism produces uric acid which is further increased in cases of anaerobic respiration and conditions like hypertension. Xanthine Oxidase inhibitors (i.e., allopurinol and febuxostat) are effective in treatment of hyperuricemia due to excessive uric acid production ${ }^{5}$.

The prevalence of hypertension is around $21.6 \%$ in males and $8.6 \%$ in females in normal population. Previous local literature indicated that in Pakistani population the prevalence of Hyperuricemia in Hypertensive patients was 65\% which was considerably higher than the expected rate $^{6}$. Hypertension is also a major risk factor for cardiovascular mortality which is the leading cause of death worldwide with about 17.4 million 
annually7. Studies have shown that a blood pressure of $160 \mathrm{~mm} \mathrm{Hg}$ or higher in absence of target organ damage and diabetes or cardiovascular disease is independently associated with poorer mortality ${ }^{8}$.

Hypertension is also a major contributing risk factor for Cerebrovascular accidents such as hemorrhagic infarct, subarachnoid hemorrhage and other intra and extra cerebral bleeds ${ }^{9}$. Blood pressure control amongst patients of type 2 Diabetes has also shown to reduce both micro and macro vascular complications ${ }^{10,11}$.

Hyperuricemia not only increase the risk of development of hypertension but also found to be increased in established hypertension. It was found that an increase in serum uric levels by 1 $\mathrm{mg} / \mathrm{dl}$ increased the prevalence of hypertension by 1.2-fold. Lowering the levels of uric acid has shown to reduce the blood pressure in young obese individuals ${ }^{12}$. Uncontrolled Blood Pressure related to high serum uric acid levels can present even without other features of metabolic syndrome so Uric acid levels need to be taken into considerations in strategies for BP management ${ }^{13}$.

Our study is aimed at delineating an association between essential hypertension and hyperuricemia in the absence of other confounding factors. Also studied during our research was the effect of age on uric acid levels in hypertensive patients. In our population, such an association could be helpful in the development of future anti-hypertensive strategies and better management of blood pressure.

\section{METHODOLOGY}

It was a cross sectional analytical study, that was carried out at Combined Military Hospital, Abbottabad, from September 2016 to February 2017. Sample size (n) was 137 and was calculated using WHO sample size calculator with margin of error 5\%, confidence interval 95\%, anticipated population proportion $65 \%$ and absolute precision required 0.08. Hypertension was defined as blood pressure of $\geq 140 \backslash 90 \mathrm{mmh}$ on two occasions, measured as per parameters, described in JNC-8 guidelines. Hyperuricemia was labeled as serum uric acid level greater than $6.97 \mathrm{mg} / \mathrm{dl}$ for males and more than $6.0 \mathrm{mg} / \mathrm{dl}$ for Females.

Non-probability consecutive sampling technique was employed. Having taken approval from hospital Research Ethics Committee and informed consent, patients from both genders, having age between 18 to 70 years, presenting in and out patient departments with hypertension, according to operational definition, were enrolled in the study. People with secondary hypertension, gout, diabetes mellitus, chronic kidney disease, psoriasis, BMI $>30$ and using thiazide diuretics were excluded from data collection. Serum uric acid levels were measured using Selectra $\mathrm{XL}$ chemical analyzer having normal references range of 2.52-6.97 mg/dl for males and 1.51-6.0 $\mathrm{mg} / \mathrm{dl}$ for females. Tests were carried out at Combined Military Hospital Abbottabad laboratory. All the reports were verified by Pathologist.

Data was entered and analyzed using SPSS version 20. For quantitative variables like age, serum uric acid levels, blood pressure and BMI, mean \pm SD was calculated. For qualitative variables like gender, normouricemia and hyperuricemia frequency and percentage was calculated. Post-stratification chi-square test was applied and $p$-value $\leq 0.05$ was taken as significant.

\section{RESULTS}

A total of 137 patients were enrolled in the study. Among them, 83 (61\%) were male while $54(39 \%)$ were female. Mean age of the patients was $56.09 \pm 09.36$ years with minimum age 37 and maximum 70 years. Seventy six $(55.50 \%)$ patients had age greater than 55 while $61(44.50 \%)$ patients were younger than or equal to the age of 55 . Mean weight, height and BMI of the patients were $67.99 \pm 6.91 \mathrm{~kg}$ (ranging from 54 to $84 \mathrm{~kg}$ ), $1.63 \pm 0.08 \mathrm{~m}$ (ranging from 1.44 to $1.83 \mathrm{~m}$ ) and $25.32 \pm 2.15 \mathrm{~kg} / \mathrm{m}^{2}$ (ranging from 20.4 to $29.9 \mathrm{~kg}$ / $\left.\mathrm{m}^{2}\right)$ respectively. Maximum systolic blood pressure was $193 \mathrm{mmHg}$ and minimum was 143 with mean of $166.71 \pm 13.67 \mathrm{mmHg}$. Similarly, maximum diastolic blood pressure was $121 \mathrm{~mm} \mathrm{Hg}$ and minimum was $90 \mathrm{mmHg}$ with mean of $100.15 \pm 8.84 \mathrm{mmHg}$. Mean serum uric acid level 
was $6.96 \pm 0.82 \mathrm{mg} / \mathrm{dl}$ with range of 8.44 to 4.93 $\mathrm{mg} / \mathrm{dl}$. Frequency of hyperuricemia was found in 102 (74.45\%) while Normouricemia in 35 (25.55\%) patients as shown in figure.

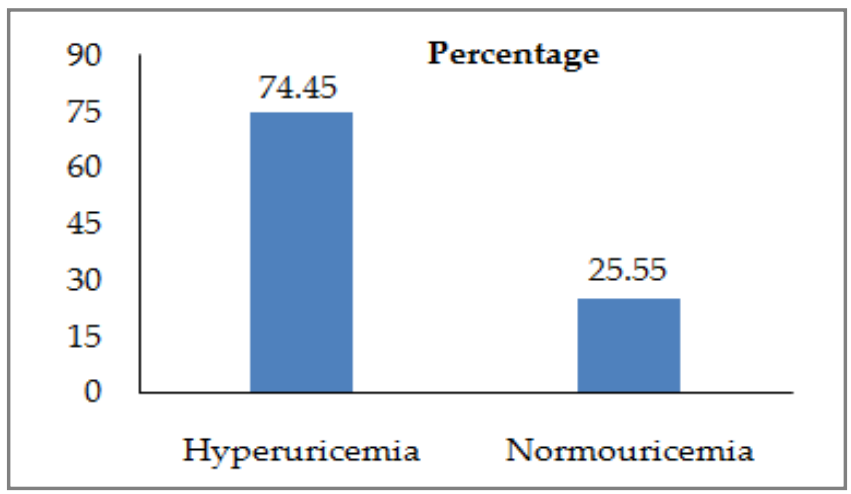

Figure: status of hyperuricemia $(n=137)$.

Table-I: Comparison of uricemia status with age of female patients.

\begin{tabular}{l|c|c|c}
\hline \multirow{2}{*}{$\begin{array}{l}\text { Age } \\
\text { (years) }\end{array}$} & \multicolumn{2}{|c|}{ Status of Uricemia } & \multirow{2}{*}{$\begin{array}{c}\text { - } \\
\text { value }\end{array}$} \\
\hline$\leq 55$ & Hyperuricemia & Normouricemia & \\
\hline$>55$ & $23(85.18 \%)$ & $4(14.81 \%)$ & \multirow{2}{*}{0.033} \\
\hline
\end{tabular}

Table-II: Comparison of uricemia status with age of male patients.

\begin{tabular}{l|c|c|c}
\hline \multirow{2}{*}{$\begin{array}{l}\text { Age } \\
\text { (years) }\end{array}$} & \multicolumn{2}{|c|}{ Status of Uricemia } & $p$ - \\
\cline { 2 - 3 } & Hyperuricemia & Normouricemia & \\
\hline$\leq 55$ & $23(67.65 \%)$ & $11(32.35 \%)$ & \multirow{2}{*}{0.143} \\
\hline$>55$ & $40(81.63 \%)$ & $9(18.37 \%)$ & \\
\hline
\end{tabular}

Table-III: Comparison of uricemia status with gender of the patients.

\begin{tabular}{l|c|c|c}
\hline \multirow{2}{*}{ Gender } & \multicolumn{2}{|c|}{ Status of Uricemia } & \multirow{2}{*}{$\begin{array}{c}\boldsymbol{p}- \\
\text { value }\end{array}$} \\
\cline { 2 - 3 } & Hyperuricemia & Normouricemia & \multirow{2}{*}{0.629} \\
\hline Male & $63(75.9 \%)$ & $20(24.1 \%)$ & \\
\hline Female & $39(72.22 \%)$ & $15(27.8 \%)$ & \\
\hline
\end{tabular}

\section{DISCUSSION}

The relationship between high serum uric acid levels and development and progression of hypertension has been a topic of interest for researchers over the last few years. This is because of the morbidity and mortality associated with hypertension and its consequences. Hyperuricemia in itself has detrimental effects on human physiology and a further association with hypertension would only compound the harmful nature of this by-product. Our study results showed that there was an increased incidence of hyperuricemia in patients of hypertension. Conversely, our study results also showed that age did not have any significant effect on the uric acid levels in hypertensive patients. When we compared the results of our study with those of other studies conducted with similar parameters in different parts of the world, following comparisons and similarities were drawn which will be elaborated further in subsequent discussion.

In one study carried out by Tanaguchi et al in Osaka, Japan, it was observed in male population, that patients with hyperuricemia were more likely to develop hypertension than those with normal uric acid levels ${ }^{14}$. This is in consonance with the conclusions drawn in our study.

In one of the studies carried out by Dasti et al in 2015 in a rural setting within Pakistan, the frequency of hyperuricemia was found to be $65 \%$ in hypertensive patients, having a mean value of serum uric acid level of 13.74. This was also found to be statistically significant with reference to age $(p<0.01)$ and gender $(p<0.05)^{6}$. This varies from our study in that whereas we did find a positive association between hyperuricemia and hypertension, no such association was seen in terms of age.

In another study carried out within Pakistan, Bilal et al found that hyperuricemia was found to be present in approximately $42 \%$ of hypertensive patients. This was less than the previously quoted study. Similar to our study, Bilal et al did not find any significant association between age and hyperuricemia in these patients, having $p$-value of 0.380. Age group 30 to 55 years showed hyperuricemia was present in $44 \%$ of patients and above 55 years it was found in $45 \%$ of hypertensive patients ${ }^{15}$.

A study carried out in Sub Himalayan India by Raina et al revealed that the prevalence of hyperuricemia was higher in hypertensive patients then normotensive patients $(p<0.05)$. This study also elaborated on the effect of gender on uric acid levels in both hypertensive and normotensive patients and showed that not only was the prevalence of hyperuricemia higher in male patients as compared to female hypertensive pati- 
ents but mean serum uric acid level was also higher in male patients as compared to females ${ }^{16}$.

Mazza et al concluded in their study carried out in 2017 that hypertensive patients with raised uric acid levels were at a higher risk of developing resistant hypertension i.e. hypertension not controlled with at least 3 first line anti-hypertensive medicine than normouricemic patients. This further substantiates the effects of hyperuricemia on hypertension ${ }^{17}$.

Adejumo et al conducted a study in Nigeria in 2017 in which they studied the effects of hyperuricemia on patients of pre dialysis Chronic Kidney Disease patients. In their study they also observed that patients with normal uric acid levels were more likely to have a better controlled blood pressure and were more likely to survive longer without the requirement of dialysis than those with raised uric acid levels ${ }^{18}$. Similar results were also seen in an Indian study conducted by Sircar et al where they observed that controlling hyperuricemia by using Febuxastat in Chronic Kidney Disease patients not only improved glomerular filtration rate but also improved blood pressure control ${ }^{19}$. Both these studies high light the role of uric acid in progression of disease in hypertensive patients.

Finally in a Chinese study carried out by Wang et al in 2016, it was observed that hyperuricemia was more frequent in hypertensive patients that in normotensive patient with other features of metabolic syndrome. There was also an association seen between obesity and higher uric acid levels in this study, however our study did not focus on this variable ${ }^{20}$.

In our study, frequency of hyperuricemia was found in $74.45 \%$ of hypertensive patients; however it is not associated with age of the patients. In male patients hyperuricemia was present in $67.65 \%$ patients aged 55 years or less and in $81.63 \%$ of patients with age over 55 years with a $p$-value of 0.193 . In female patients, hyperuricemia was present in $85.18 \%$ of patients aged less than 55 years and in $59.25 \%$ in patients aged over 55 years with a $p$-value of 0.033 .
It was therefore recommended that more studies should be done on the subject to enhance the epidemiological basis and more diverse parameters may be studied independently to further clarify the role of each variable in the development of hypertensive complications. Studies should also be carried out to find out the effects of treating raised uric acid levels on the development and progression of hypertension and other cardiovascular risk factors in our population.

\section{CONCLUSION}

There was association between uric acid level and hypertension. Frequency of hyperuricemia was found higher in hypertensive patients and there was no association between hyperuricemia and age of patient.

\section{CONFLICT OF INTEREST}

This study has no conflict of interest to be declared by any author.

\section{REFERENCES}

1. Ansari R, Gandhi R, Saiyed M, Jain K. Study of prevalence and impact of hyperuricemia in a patient of hypertension. Int J Adv Med 2017; 4(2): 367.

2. Lim SS, Vos T, Flaxman AD, Danaei G, Shibuya K, Rohani HA, et al. A comparative risk assessment of burden of disease and injury attributatable to 67 risk factors and risk factor clusters in 21 regions, 1990-2010: a systematic analysis for the Global Burden of disease study 2010. Lancent 2013; 380(9859): 2224-60.

3. Aziz K, Faruki M, Manolio T, Davis CE Abernathy J. Blood pressure and hypertension distribution in lower middle class urban society in Pakistan. J Pak Med Assoc 2005; 55(8): 333-38.

4. Zhang X, Meng Q, Feng J, Liao H. The prevalence of hyperuricemia and its correlates in ganzi tibetan auto-nomous prefecture, sichuan Province, China. Lipids Health Dis 2018; 17(1): 235.

5. Raja S, Kumar A, Aahooja RD, Thakuria U, Ochani S, Shaukat F. Frequency of hyperuricemia and its risk factors in the adult population. Cureus 2019; 11(3): e4198.

6. Dasti D, Hashmi DA, Shah D, Hussain D, Gohar D, Farah D, et al. Essential hypertension; hyperuricemia in patients. Professional Med J Q 2015; 22(12): 1555-59.

7. Naghavi M, Wang H, Lozano R, Davis A, Liang X, Zhou M, et al. Global, regional, and national age-sex specific all-cause and cause-specific mortality for 240 causes of death, 1990-2013: a systematic analysis for the Global Burden of Disease Study 2013. Lancet 2015; 385(9963): 117-71.

8. Lonn E, Bosch J, López-Jaramillo P, Zhu J, Liu L, Pais P et al. Blood-Pressure lowering in intermediate-risk persons without cardiovascular disease. New Eng J Med 2016; 374(21): 2009-20.

9. Arboix A. Cardiovascular risk factors for acute stroke: Risk profiles in the different subtypes of ischemic stroke. World J Clin Cases 2015; 3(5): 418-29.

10. Emdin C, Rahimi K, Neal B, Callender T, Perkovic V, Patel A. Blood pressure lowering in type 2 diabetes. J Am Med Assoc 2015; 313(6): 603-05. 
11. Brunström M, Carlberg B. Effect of antihypertensive treatment at different blood pressure levels in patients with diabetes mellitus: systematic review and meta-analyses. Bio Med J 2012; 30: e130.

12. Kuwabara M. Hyperuricemia, cardiovascular disease, and hypertension. Pulse 2016; 3(3-4): 242-52.

13. Cho J, Kim C, Kang D, Park J. Hyperuricemia and uncontrolled hypertension in treated hypertensive patients. Medicine 2016; 95(28): e4177.

14. Taniguchi Y, Hayashi T, Tsumura K, Endo G, Fujii S, Okada K. Serum uric acid and the risk for hypertension men: The Osaka Health Survey. J Hypertens 2001; 19(7): 1209-15.

15. Bilal MH, Tahir M. Frequency of hyperuricemia in hypertensive patients presenting at DG Khan Hospital, DG Khan. Pak J Med Health Sci 2015; 9(2): 547-49.

16. Raina S, Agarwal VK, Kapoor D, Sharma KN, Yadav RS. Hypertension as determinant of hyperuricemia: a case control study from the sub-himalayan region in North India. J Assoc Physi- cians India 2018; 66(2): 14-17.

17. Mazza A, Lenti S, Schiavon L, Monte A, Townsend D, Ramazzina E, et al. Asymptomatic hyperuricemia is a strong risk factor for resistant hypertension in elderly subjects from general population. Biomed Pharmacother 2017; 86(1): 590-94.

18. Adejumo O, Okaka E, Okwuonu C, Ojogwu L. Hyperuricemia in predialysis chronic kidney disease patients in Southern Nigeria. Sahel Med J 2016; 19(1): 21.

19. Sircar D, Chatterjee S, Waikhom R, Golay V, Raychaudhury A, Chatterjee S, et al. Efficacy of febuxostat for slowing the gfr decline in patients With CKD and asymptomatic hyperuricemia: a 6-month, double-blind, randomized, placebo-controlled trial. Amer J Kidney Dis 2015; 66(6): 945-50.

20. Wang ZN, Li P, Jiang RH, Li L, Li X, Li L, et al. The association between serum uric acid and metabolic syndrome among adolescents in northeast China. Int J Clin Exp Med 2015; 8(11): 21122-29. 